\title{
The effect of a pediatric heat and moisture exchanger on dead space in healthy pediatric anesthesia
}

\author{
Min A Kwon \\ Department of Anesthesiology and Pain Medicine, Dankook University College of Medicine, Cheonan, Korea
}

Background: Heat and moisture exchangers (HME) are often used to maintain humidity of breathing circuits during anesthesia. It is also known to increase dead space ventilation in respiratory distress syndromes. However, the effect of a pediatric HME in healthy pediatric patients has not yet been clarified. The purpose of this study was to evaluate the effect of a pediatric HME on dead space in healthy pediatric patients during anesthesia.

Methods: 20 ASA physical class I pediatric patients, without respiratory impairment, who underwent elective surgery for inguinal hernia or hydrocele with general anesthesia were enrolled. Fifteen minutes after ventilation with and without pediatric $\mathrm{HME}$ (internal volume of $22 \mathrm{ml}$ ), hemodynamic variables, end tidal $\mathrm{CO}_{2}$, minute volume and airway pressure were measured, and arterial blood sampling was conducted simultaneously.

Results: The removal of pediatric $\mathrm{HME}$ decreased $\mathrm{PaCO}_{2}$ significantly from $46.1 \pm 6.9 \mathrm{mmHg}$ to $37.9 \pm 4.3 \mathrm{mmHg}(\mathrm{P}<$ $0.001)$ and increased the $\mathrm{pH}$ from 7.32 to $7.37(\mathrm{P}<0.001)$. The differences between $\mathrm{PaCO}_{2}$ with and without $\mathrm{HME}(\Delta$ $\left.\mathrm{PaCO}_{2}\right)$ were significantly correlated with weight $(\mathrm{P}<0.001, \beta 1=-0.749)$ and age $(\mathrm{P}=0.002, \beta 1=-0.623)$.

Conclusions: The use of a pediatric HME significantly increased $\mathrm{PaCO}_{2}$ in healthy pediatric patients that was inversely proportional to weight and age. The use of pediatric HME should be carefully considered in small pediatric patients. (Korean J Anesthesiol 2012; 62: 418-422)

Key Words: Dead space, Heat-moisture exchanger, Pediatric anesthesia.

\section{Introduction}

Heat-and-moisture exchangers (HME) are the most commonly used humidi-filters. HME have a low resistance to airway flow and a relatively small volume (about $75 \mathrm{ml}$ ), which is not too large to impair ventilation of healthy adult patients ventilated with a tidal volume of $8-12 \mathrm{ml} / \mathrm{kg}[1,2]$. Therefore, most studies to evaluate the dead space effect of HME in adult patients have been conducted in ICU patients receiving lung protective ventilation with a lower tidal volume of $4-6 \mathrm{ml} / \mathrm{kg}[1,3]$.

However, with the exception of extremely small premature neonates [4], most pediatric patients undergoing general

Received: March 16, 2011. Revised: 1st, August 25, 2011; 2nd, October 20, 2011. Accepted: October 24, 2011.

Corresponding author: Min A Kwon, M.D., Department of Anesthesiology and Pain Medicine, Dankook University College of Medicine, 16-5, Anseo-dong, Dongnam-gu, Cheonan 330-715, Korea. Tel: 82-41-550-3918, Fax: 82-41-550-6819, E-mail: mmauss@hanmail.net

(c) This is an open-access article distributed under the terms of the Creative Commons Attribution Non-Commercial License (http:// creativecommons.org/licenses/by-nc/3.0/), which permits unrestricted non-commercial use, distribution, and reproduction in any medium, provided the original work is properly cited. 
anesthesia are applied with only one size of pediatric HME between the tracheal adaptor and the Y piece. The volume of a pediatric HME is generally $20-25 \mathrm{ml}$, which is about $1 / 10$ of the tidal volume of a $20 \mathrm{~kg}$ patient or $1 / 5$ for a $10 \mathrm{~kg}$ patient. Even when used in patients that are healthy without acute lung disease, smaller pediatric patients would be affected by the use of a pediatric HME.

One previous study was conducted to evaluate the effect of humidi-filters on dead space in pediatric patients [5]. However, that study examined how much more ventilation and breathing work were required to maintain the same end-tidal concentration of $\mathrm{CO}_{2}\left(\mathrm{EtCO}_{2}\right)$, but not the $\mathrm{PaCO}_{2}$, in pediatric patients under 2 years old. However, when there was a big dead space ventilation, the $\mathrm{EtCO}_{2}$ could not be representative of $\mathrm{PaCO}_{2}$ and the ages of the study population were limited to under 2 years.

Therefore, in this study, we examined whether the $\mathrm{PaCO}_{2}$ of healthy pediatric patients (1-96 months) was significantly influenced by the use of pediatric HME. Moreover, we investigated the correlation between the effect of pediatric HME on $\mathrm{CO}_{2}$ elimination and demographic variables.

\section{Materials and Methods}

With approval from the ethics committee, we obtained written, informed consent from all the conservators of 20 patients who were ASA I, aged 1-96 months and scheduled to undergo elective surgical procedures. Exclusion criteria included abnormal airway, lung disease, a history of admission to the NICU due to prematurity or respiratory distress syndrome, acute respiratory infection, fever $\left(>37.5^{\circ} \mathrm{C}\right)$ or hemodynamic instability.

The patients were administered $1 \mathrm{mg} / \mathrm{kg}$ of ketamine and $5 \mathrm{ug} / \mathrm{kg}$ of glycopyrrolate in the preanesthetic room. After loss of consciousness, the patients were delivered to the operating room. The lungs were ventilated manually with $6 \mathrm{~L} / \mathrm{min}$ of $100 \%$ oxygen and 6 vol\% sevoflurane using a rebreathing circuit (Primus ${ }^{\odot}$, Draeger Medical, USA) and rocuronium $0.6 \mathrm{mg} / \mathrm{kg}$ was administered. Endotracheal intubation was conducted and the patients were ventilated with $\mathrm{FiO}_{2} 0.5$ and sevoflurane in the supine position. A $24 \mathrm{G}$ catheter was inserted into the radial artery for invasive blood pressure monitoring. During the study, the heart rate (HR), mean arterial blood pressure (MAP) and oxygen saturation $\left(\mathrm{SpO}_{2}\right)$ were monitored continuously. Patients were hydrated with lactated Ringer's solution. Ventilatory settings were: tidal volume (Vt) of $10 \mathrm{ml} /$ $\mathrm{kg}$, frequency of $12-20 / \mathrm{min}$ depending on weight and an I/E ratio of $1: 1.5$ or $1: 2$ (freq $<14 / \mathrm{min}$ ). The frequency of ventilation was $20 / \mathrm{min}$ for $0-5 \mathrm{~kg}, 18 / \mathrm{min}$ for $5-10 \mathrm{~kg}, 16 /$ min for $10-15 \mathrm{~kg}, 14 / \mathrm{min}$ for $15-20 \mathrm{~kg}$ or $12 / \mathrm{min}$ for $20-$
$30 \mathrm{~kg}$. During the study period, the ventilation setting was not changed. First, we connected the pediatric HME in the breathing circuit for 15 minutes for stabilization (1). We used one size of pediatric HME (Humidi-filter ${ }^{\circledR}$, Acemedical, South Korea) with an internal volume of $22 \mathrm{ml}$. The HME was placed between the tube connector and the Y piece of the circuit. Sampling ports for gas analysis were connected at a right-angled endotracheal tube adaptor. Fifteen minutes after ventilation with the HME, we measured hemodynamic variables including heart rate (HR), mean arterial blood pressure (MBP), $\mathrm{EtCO}_{2}$, minute volume [6] and airway pressure. Arterial blood sampling was conducted simultaneously. Then, lungs were ventilated without HME for 15 minutes and we examined the same variables and arterial blood gas. The dead space and A-Et $\mathrm{PCO}_{2}$ differences were also compared before and after the use of HME. Dead space $\left(\mathrm{V}_{\mathrm{D}} /\right.$ $\left.\mathrm{V}_{\mathrm{T}}\right)$ was calculated using the Bohr equation: $\mathrm{V}_{\mathrm{D}} / \mathrm{V}_{\mathrm{T}}(\%)=\left(\mathrm{PaCO}_{2}\right.$ - $\left.\mathrm{EtCO}_{2}\right) / \mathrm{PaCO}_{2}[1]$. Because $\mathrm{CO}_{2}$ production was proportional to cardiac output, the anesthetic depth and fluid management were controlled to maintain a similar MAP and HR. Correlation between demographic variables such as age or weight and the difference of $\mathrm{PaCO}_{2}$ with and without the HME were examined.

A power analysis indicated that a sample size of 20 was required to detect significant differences of $\mathrm{PaCO}_{2}$ of more than $5 \mathrm{mmHg}$ between patients with and without the HME filter (power 90\%, $\alpha$ error $=0.05$ ). Statistical analysis was conducted using a paired t-test and a signed rank test. A causal relationship was revealed by Pearson's correlation test and a quadrantic equation with a curve estimation regression test. Data were expressed as the means \pm SD or median (range). All statistical calculations were conducted using the SPSS 12.0 Inc., Chicago, IL, USA. Statistical significance was defined as $\mathrm{P}<0.05$.

\section{Results}

Demographic data are presented in Table 1. The ages of the patients ranged from 1 month to 96 months. Their weights ranged from 3.38 to $27 \mathrm{~kg}$ and normally distributed. Male gender $(16 / 20,80 \%)$ was significantly predominant because we enrolled patients with hydrocele or inguinal hernia, which are much more prevalent in male children [7]. Heart rate, mean blood pressure and oral temperature were similar in patients.

Table 1. Patient Characteristics

\begin{tabular}{lc}
\hline Sex $(\mathrm{M} / \mathrm{F})$ & $16 / 4$ \\
Age $(\mathrm{Mo})$ & $14.0(5.7-44.2)$ \\
Height $(\mathrm{cm})$ & $75.1 \pm 21.1$ \\
Weight $(\mathrm{kg})$ & $13.4 \pm 6.2$ \\
Name of surgery & 18 \\
Hernioplasty & 2 \\
Hydrocelectomy & \\
\hline
\end{tabular}


In this study, it was shown that $\mathrm{EtCO}_{2}$ with $\mathrm{HME}$ was not representative of $\mathrm{PaCO}_{2}$ in small pediatric patients. If the weight of the patient was small, the difference between end-tidal $\mathrm{CO}_{2}$ and $\mathrm{PaCO}_{2}\left(=\mathrm{A}\right.$-Et $\mathrm{PCO}_{2}$ ) with HME increased significantly (R square $=0.444, \mathrm{P}=0.009$; Fig. 1 ). Maintenance of the same level of $\mathrm{EtCO}_{2}$ in smaller patients can make them in a risk of hypercapnia. With the removal of HME for 15 minutes, the $\mathrm{PaCO}_{2}$ decreased significantly from $46.1 \pm 6.9 \mathrm{mmHg}$ to $37.9 \pm 4.3$ $\mathrm{mmHg}(\mathrm{P}<0.001)$ and the arterial blood $\mathrm{pH}$ increased from 7.32 to $7.37(\mathrm{P}<0.001$; Table 2$)$. Other respiratory parameters were not changed.

The differences between $\mathrm{PaCO}_{2}$ with and without $\mathrm{HME}(\Delta$ $\left.\mathrm{PaCO}_{2}\right)$ were significantly correlated with weight $(\mathrm{P}<0.001, \beta 1$ $=-0.749)$ and age $(\mathrm{P}=0.002, \beta 1=-0.623)$. The removal of HME reduced $\mathrm{PaCO}_{2}$ severely in the younger patients $\left(\triangle \mathrm{PaCO}_{2}=12.4-\right.$ $0.191 \times$ age $(\mathrm{mo})+0.001 \times$ age $(\mathrm{mo})^{2}, \mathrm{R}$ square $=0.397 ; \mathrm{P}=0.011$ - Fig. 2) and in the smaller patients $\left(\Delta \mathrm{PaCO}_{2}=26.0-1.894 \times\right.$ wt $(\mathrm{kg})+0.038 \times$ wt $(\mathrm{kg})^{2}, \mathrm{R}$ square $=0.637 ; \mathrm{P}<0.001 ;$ Fig. 3).

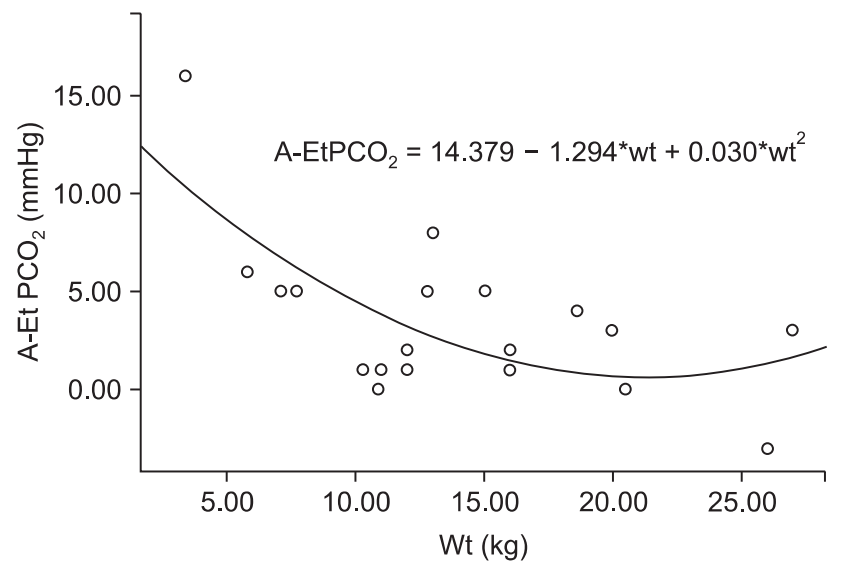

Fig. 1. Regression of A-Et $\mathrm{PCO}_{2}$ (the difference between end tidal $\mathrm{CO}_{2}$ and $\mathrm{PaCO}_{2}$ ) with a heat and moisture exchanger and weight. $* \mathrm{P}<0.05$.

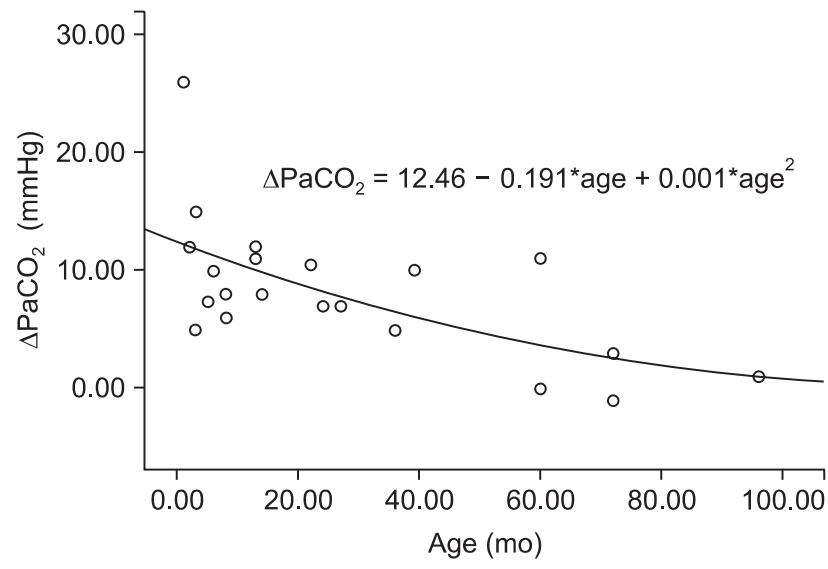

Fig. 2. Regression of the difference between $\mathrm{PaCO}_{2}$ with or without a heat-moisture exchanger $\left(\Delta \mathrm{PaCO}_{2}\right)$ and age. ${ }^{*} \mathrm{P}<0.05$.

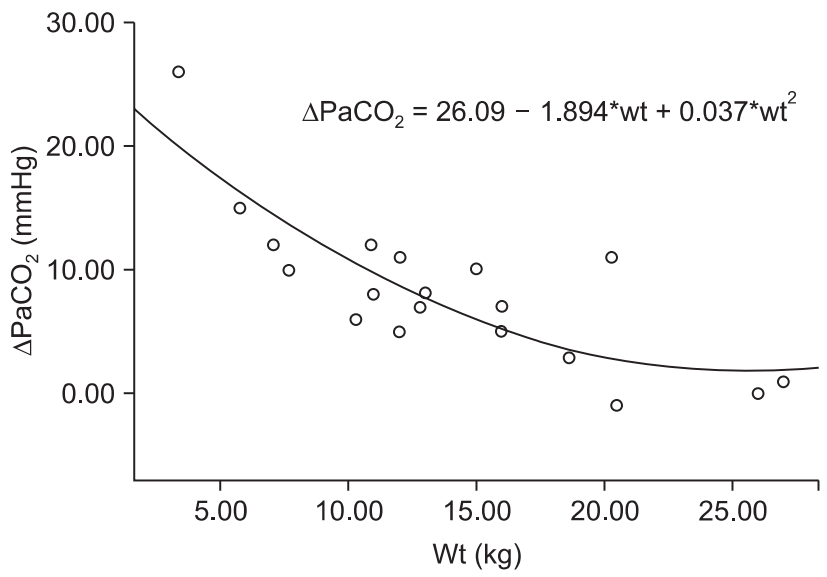

Fig. 3. Regression of the difference of $\mathrm{PaCO}_{2}$ with and without a heat and moisture exchanger $\left(\Delta \mathrm{PaCO}_{2}\right)$ and weight. ${ }^{*} \mathrm{P}<0.05$.

Table 2. Ventilatory and Hemodynamic Variables

\begin{tabular}{lccc}
\hline & With HME & Without HME & P value \\
\hline $\mathrm{EtCO}_{2}(\mathrm{mmHg})$ & $42.9 \pm 5.7$ & $36.1 \pm 5.7$ & $\mathrm{P}<0.001^{*}$ \\
$\mathrm{PaCO}_{2}(\mathrm{mmHg})$ & $46.0 \pm 6.9$ & $37.9 \pm 4.3$ & $\mathrm{P}<0.001^{*}$ \\
$\mathrm{TVe}(\mathrm{ml})$ & $133.1 \pm 60.9$ & $134.4 \pm 61.6$ & $\mathrm{NS}$ \\
$\mathrm{Ve}(\mathrm{L})$ & $2.1(1.6-2.5)$ & $2.1(1.7-2.5)$ & $\mathrm{NS}$ \\
$\mathrm{A}-\mathrm{Et} \mathrm{PCO}_{2}(\mathrm{mmHg})$ & $3.19 \pm 3.88$ & $1.81 \pm 3.81$ & $\mathrm{NS}$ \\
$\mathrm{Vd} / \mathrm{Vt}(\%)$ & $6.4 \pm 7.4$ & $4.8 \pm 10.8$ & $\mathrm{NS}$ \\
$\mathrm{PP}(\mathrm{cmH} 2 \mathrm{O})$ & $12.0(9.7-14.0)$ & $13.0(9.7-14.2)$ & $\mathrm{NS}$ \\
$\mathrm{HR}(\mathrm{bpm})$ & $149.4 \pm 19.7$ & $146.9 \pm 21.6$ & $\mathrm{NS}$ \\
$\mathrm{MBP}(\mathrm{mmHg})$ & $71.6 \pm 11.7$ & $67.9 \pm 18.2$ & $\mathrm{NS}$ \\
$\mathrm{Hematocit}(\%)$ & $31.0(26.5-32.0)$ & $29.0(25.5-33.0)$ & $\mathrm{NS}$ \\
\hline
\end{tabular}

Data are expressed as the means $\pm \mathrm{SD}$ or median (range). HME: heat and moisture exchangers, $\mathrm{EtCO}_{2}$ : end tidal $\mathrm{CO}_{2} \mathrm{concentration} \mathrm{PaCO}_{2}$, partial pressure of arterial $\mathrm{CO}_{2}$, TVe: expiratory tidal volume, Ve: minute ventilation, A-Et $\mathrm{PCO}_{2}$ : the difference in arterial to end tidal concentration of $\mathrm{CO}_{2}, \mathrm{Vd} / \mathrm{Vt}(\%)$ : dead space, $\mathrm{PP}$ : plateau pressure. $* \mathrm{P}<0.05$. 
There was no patient with higher than $60 \mathrm{mmHg}$ of $\mathrm{PaCO}_{2}$ during the study. All patients were recovered without any complications.

\section{Discussion}

The upper airway maintains humidification and protects the lungs from the environment by acting as a filter. Because mechanical ventilators with endotracheal intubation bypass the upper airway, an artificial humidifier and filter should be included in such systems [3]. The devices for humidification include heated humidifiers (HH) and HME. HH are more expensive and bulky, but have no dead space in the circuit. Conversely, HME are inexpensive and simple, but have a negative effect on ventilation because of their internal dead space volume [8].

Physiologic dead space is composed of alveolar dead space and anatomical dead space. Normally, the physiologic dead space is $2.2 \mathrm{ml} / \mathrm{kg}$, which is about one third of the tidal volume [9]. When mechanical ventilation is conducted during general anesthesia, apparatus dead space is added due to the presence of the endotracheal tube, tube adaptor, Y piece and a humidification-filter device such as an HME.

Most pediatric patients have compliant and healthy lungs, with minimal alveolar dead space. However, the anatomical dead space of pediatric patients is larger than adult patients because the size of the head is relatively larger to their body [9].

Moreover, if there were a large apparatus dead space, the dead space volume could be most of the tidal volume, which would result in ineffective ventilation and the development of respiratory acidosis. In high dead space settings, $\mathrm{CO}_{2}$ elimination is not sufficient, even with elevated ventilatory frequencies. Several possible complications following insufficient ventilation and severe respiratory acidosis include air trapping in the lungs and the development of an intrinsic positive end-respiratory pressure with consequential increases in intrathoracic pressure, reduced venous return, higher intracranial pressure and $\mathrm{CO}_{2}$ narcosis [1].

The results of this study demonstrated that the addition of pediatric $\mathrm{HME}$ increased $\mathrm{PaCO}_{2}$ significantly even in pediatric patients without any lung disease, while the removal of the HME decreased $\mathrm{PaCO}_{2}$ significantly that was inversely proportional to weight and age.

It should be noted that there were some distinguishing characteristics between this study and previously conducted studies. First, we inserted an arterial cannulation and examined real time blood pressure monitoring and arterial blood gas. A previous study [5] used noninvasive blood pressure monitoring and $\mathrm{EtCO}_{2}$ as a ventilation index. In that study, the same $\mathrm{EtCO}_{2}$ was maintained despite the use of HME and the amount of ventilation and airway pressure was compared. In normal children, $\mathrm{EtCO}_{2}$ is closely correlated with $\mathrm{PaCO}_{2}$ [10]. However, the additional HME adds a considerable dead space volume to the small tidal volume of children. We found that A-Et $\mathrm{PCO}_{2}$ with HME was closely related to the weight in a negatively curvilinear fashion (Fig. 1); that is, the difference between $\mathrm{PaCO}_{2}$ and $\mathrm{EtCO}_{2}$ was higher in smaller patients. Only the use of $\mathrm{EtCO}_{2}$ as the ventilation index can cause hypercapnia in younger patients. Therefore, we thought that invasive $\mathrm{PaCO}_{2}$ was necessary to reveal the effect of this large apparatus dead space. In addition, if we connected the $\mathrm{CO}_{2}$ sampling port to the port in the pediatric HME that was more proximal than the tube adaptor, $\mathrm{EtCO}_{2}$ sampled in the HME would be less than that sampled in a tube adaptor $[5,11]$; then the difference between $\mathrm{PaCO}_{2}$ and $\mathrm{EtCO}_{2}$ would increase. If we used only $\mathrm{EtCO}_{2}$ as a ventilation index in small children, we would overestimate the degree of ventilation and miss significant hypercapnia.

Production of $\mathrm{CO}_{2}$ is proportional to cardiac output. Therefore, we controlled the blood volume status and anesthetic depth via the arterial line to maintain a similar cardiac output in this study. Moreover, we only enrolled patients without fever, acute lung disease or a history of intensive lung care during the neonatal period. Patients undergoing laparotomy were also excluded because of the potential for large fluid management. The alveolar dead space, calculated using the Bohr equation, was similar and minimal during the study period.

We also revealed a correlation between the $\mathrm{PaCO}_{2}$ difference with the use of a HME and demographic data such as weight or age. This was because only one size of pediatric HME is used in most pediatric patients. According to the regression formula, a healthy patient weighing more than $25 \mathrm{~kg}$ is free from the dead space effect of a pediatric HME. If the weight of the patient was $18 \mathrm{~kg}$, the use of a HME would increase the $\mathrm{PaCO}_{2}$ by $5 \mathrm{mmHg}$, while a weight of $11 \mathrm{~kg}$ would lead to an increase of the $\mathrm{PaCO}_{2}$ as high as $10 \mathrm{mmHg}$ and a weight of $3.5 \mathrm{~kg}$ would increase $\mathrm{PaCO}_{2}$ to $20 \mathrm{mmHg}$. Chau et al. [5] suggested that elevated airway pressure and frequencies were needed to overcome hypercapnia caused by the use of a HME. Overall, the results of this study were revealing. Usually, it is thought the use of a pediatric HME was safe in healthy pediatric patients. However, there was a large increase in apparatus dead space in healthy pediatric patients, especially small patients. The removal of the HME from the circuit in pediatric patients with acute lung injury could have led to effective ventilation with significant reduction in the work of breathing. Some authors have suggested that HME also increases oxygenation via its intrinsic positive end expiratory pressure effect [8]. However, an increase in $\mathrm{PaO}_{2}$ was not observed in this study.

It should be noted that this study had some limitations. Specifically, male children were predominant in this study 
due to our patient selection. The operation for inguinal hernia is conducted mainly in males (91\%) [7]. However, we do not believe that male predominance influenced the results of this study. Moreover, we removed the HME for 15 minutes without the compensatory use of another artificial humidification device. Removing the HME necessitates the use of a more expensive heated humidifier device unless lungs are ventilated at a low fresh gas flow for a short period ( $\leq 1 \mathrm{hr}$ ) [12]. However, the cessation time of humidification was short and we used a low gas flow of $3 \mathrm{~L} / \mathrm{min}$.

As mentioned above, the use of HME is an inexpensive and effective method of humidification, but is limited by the large internal dead space. Boyer et al. [3] suggested that the small dead space of a HME could provide equal humidification when compared to a heated humidifier without altering the respiratory parameters during noninvasive ventilation of acute lung injury patients. Further investigations on pediatric HME devices with smaller dead spaces are needed, especially in small pediatric patients.

In conclusion, the use of a pediatric HME induced a significant increase in $\mathrm{PaCO}_{2}$ and respiratory acidosis, even though the patients had healthy lungs. Moreover, these changes were inversely proportional to weight and age. If there was some impaired gas exchange, the removal of a pediatric HME from the circuit could offer significant $\mathrm{CO}_{2}$ elimination and should be considered.

\section{Acknowledgements}

The present research was conducted by the research fund of Dankook University in 2009.

\section{References}

1. Hinkson CR, Benson MS, Stephens LM, Deem S. The effects of apparatus dead space on $\mathrm{PaCO}_{2}$ in patients receiving lung-protective ventilation. Respir Care 2006; 51: 1140-4.

2. Campbell RS, Davis K Jr, Johannigman JA, Branson RD. The effects of passive humidifier dead space on respiratory variables in paralyzed and spontaneously breathing patients. Respir Care 2000; 45: 306-12.

3. Boyer A, Vargas F, Hilbert G, Gruson D, Mousset-Hovaere M, Castaing $\mathrm{Y}$, et al. Small dead space heat and moisture exchangers do not impede gas exchange during noninvasive ventilation: a comparison with a heated humidifier. Intensive Care Med 2010; 36: 1348-54.

4. De Robertis E, Servillo G, Tufano R, Jonson B. Aspiration of dead space allows isocapnic low tidal volume ventilation in acute lung injury. Relationships to gas exchange and mechanics. Intensive Care Med 2001; 27: 1496-503.

5. Chau A, Kobe J, Kalyanaraman R, Reichert C, Ansermino M. Beware the airway filter: deadspace effect in children under 2 years. Paediatr Anaesth 2006; 16: 932-8.

6. Iotti GA, Olivei MC, Palo A, Galbusera C, Veronesi R, Comelli A, et al. Unfavorable mechanical effects of heat and moisture exchangers in ventilated patients. Intensive Care Med 1997; 23: 399-405.

7. Primatesta $P$, Goldacre MJ. Inguinal hernia repair: incidence of elective and emergency surgery, readmission and mortality. Int J Epidemiol 1996; 25: 835-9.

8. Le Bourdellès G, Mier L, Fiquet B, Djedaïni K, Saumon G, Coste F, et al. Comparison of the effects of heat and moisture exchangers and heated humidifiers on ventilation and gas exchange during weaning trials from mechanical ventilation. Chest 1996; 110: 12948.

9. Numa AH, Newth CJ. Anatomic dead space in infants and children. J Appl Physiol 1996; 80: 1485-9.

10. Lindahl SG, Yates AP, Hatch DJ. Relationship between invasive and noninvasive measurements of gas exchange in anesthetized infants and children. Anesthesiology 1987; 66: 168-75.

11. Rich GF, Sullivan MP, Adams JM. Is distal sampling of end-tidal $\mathrm{CO}_{2}$ necessary in small subjects? Anesthesiology 1990; 73: 265-8.

12. Poopalalingam R, Goh MH, Chan YW. The effect of heat and moisture exchanger and gas flow on humidity and temperature in a circle anaesthetic system. Singapore Med J 2002; 43: 563-5. 